\title{
SIKH KIRTAN IN THE DIASPORA: IDENTITY, INNOVATION, AND REVIVALISM
}

Navtej K. Purewal and Harjinder S. Lallie

\section{Introduction}

In 2003 the Dya Singh World Music Group, upon invitation from the Sikh Mayor of a medium-size California town with a considerable Sikh community, arrived from Australia to run a Sikh youth camp for the community in the area. For one week, Dya Singh and his group, comprised of both Sikhs and non-Sikhs, led the camp in teaching the children Gurmukhi, gurbani kirtan, and translations in accessible language and storytelling styles to the children of the Guru Granth Sahib. The appealing world music style of kirtan was performed by Dya Singh's group and the children participants on the final day of the camp in front of parents and the community, surprising many in how much the children had learnt in only one week. The immediate reaction from the Gurdwara Committee members ignited an opposition to what had gone on that week. As allegedly commented by one committee member:

He turned Darbar Sahib into an entertainment center. He even made everyone laugh with some jokes! Religion is serious business... He is blasphemous! We should never pay him or invite him here again. ${ }^{1}$

Not only does Dya Singh's group use the harmonium and tabla in its renditions of shabad kirtan, but also the aboriginal didgeridoo, the European gypsy violin, the electric guitar and other instruments in their recordings and performance, stretching the imagination and boundaries of kirtan into the realm of world music.

Dya Singh, who had won the Male Artist of the Year at the World Music Awards in Sydney, Australia only a few years earlier in 2000, in this instance was refused payment from the Gurdwara Committee for his group's time and was accused of 'selling kirtan' which, they (the Committee) argued, otherwise would be offered as seva. The committee was

\footnotetext{
1 Shyone Kaur, "The Larrikin Pied Piper from Oz," Sikh Spectrum Monthly 12 (2003): http://sikhspectrum.com/2003/05/the-larrikin-pied-piper-from-oz/.
} 
deaf to other voices in the community which were appreciative of the high impact that the week had had in invoking an interest in the children in Sikhism and kirtan. The popularisation of kirtan amongst children of the diaspora through Dya Singh's style, melodies and method, however, went far beyond the incident in this town in California and has continued to remain both a source of listening enjoyment and of more orthodox judgement. Either way, his CDs have circulated globally making his world music style a hallmark of diaspora kirtan.

Around the same time in 2002 Snatam Kaur Khalsa, a Colorado-born, California-raised member of the $3 \mathrm{HO}$ 'American Sikh' community in the U.S. inspired by Yogi Harbhajan Singh, was nominated for a Grammy Award. She became a semi-finalist and subsequently continued to maintain a presence at the top of the New Age category charts for several years to come. The projection of her image, dressed in full white flowing Sikh traditional dress and turban, made a tremendous impact and instilled a sense of pride amongst many Sikhs globally. This, of course, cannot be seen to sum up the response by Punjabi Sikhs to $3 \mathrm{HO}$ interpretive performances of kirtan. Many Punjabi Sikhs have kept an interested but watchful, often sceptical, distance from this style, which combines Celtic and Native American chants with Indian raags, and western folk and jazz music, crossing many conventions and more than veering away from the classical system of kirtan in raag and taal.

Both these examples demonstrate modernist evolutionary kirtan styles which have progressed from the medieval era of the Gurus to the present and in which modern instruments and singing styles have been combined and fused with Sikh scripture. These examples represent the evolution of a form of kirtan which originated in South Asia but has travelled across continents and been modernised by sounds and settlements of the diaspora. However not all kirtan in the diaspora applies this modernist take on kirtan. Sikh devotional music in the diaspora represents the structuring of identity through its performance which, as can be observed across different global contexts, provides a musical backdrop to currents around orthodoxy, heterodoxy and musical traditions. ${ }^{2}$ In recent years, the Sikh diaspora has observed a revivalist movement which endeavours to resist the modernisation of kirtan, and in this sense could be argued to be slanted towards a recovery exercise of traditional kirtan, and bring

\footnotetext{
2 Gurdeep J.S. Khabra, "Music of the Sikh Diaspora: Devotional Sounds, Musical Memory and Cultural Identity," Sikh Formations 8/2 2012). 147-170.
} 
the singing and performance of kirtan back to its classical roots. 'Gurmat Sangeet' refers to the form of kirtan which is performed in the style, form and raag as that of the times of the Gurus. These efforts have been led in the UK by the Raj Academy and the Gurmat Sangeet Academy. ${ }^{3}$ These academies have adopted a strong method of teaching and commitment to the practice and preservation of kirtan as a classical art form with an inclusive approach towards the involvement of Punjabi and non-Punjabi Sikhs, drawing upon the expertise and heritage of the Namdharis.

These examples of kirtan, ranging from popular new age to classical, not only exhibit kirtan's wide appeal but also illustrate the symbolic relationship to the politics of community, identification, and 'tradition'. While the modernisation of kirtan under the aegis of musicology and western orientalism in the nineteenth and twentieth centuries has been aptly explored by van der Linden, ${ }^{4}$ we endeavour to situate kirtan within the modernising influences of the contemporary globalised Sikh diaspora. Kirtan can be located within histories of the Sikh diaspora which reflect both sentiments and struggles of the times as well as notions of 'community' and identity. The diversity of religious musical practices within Sikh kirtan in the diaspora illustrates the rich social, cultural, and religious context to the performance and practice of kirtan: samagam/rainsbai kirtan of the Akhand Kirtani Jatha (AKJ), dharmik geet (religious folk) and satsang styles of kirtan, and revivalist projects to 'return' to traditional forms of kirtan performance in terms of instrumentation and the prescribed raags and taal. Sikh kirtan in the diaspora has evolved alongside the histories and processes of settlement, community building and religious movement. More recently, the internet has provided a plethora of sites from which kirtan can be listened to, downloaded, and circulated, ${ }^{5}$ further broadening the remit of kirtan in the diaspora.

This chapter aims to take stock of the circulation of kirtan in the diaspora and, in doing so, to provide an overview of how kirtan has travelled in the diaspora. Sikh identity is reflected in the popularisation of certain styles and forms of kirtan over time which need to be seen as responses to the times in which they have been circulated, practiced and performed.

\footnotetext{
3 The Gurmat Sangeet Academy is based in Birmingham and was established by Harjinder S. Lallie and Narinderjit S. Lallie.

4 Bob van der Linden, "Sikh Music and Empire: The Moral Representation of Self in Music," Sikh Formations 4/1 (2008). 1-15.

5 For one of the most comprehensive sites dedicated to the preservation, documentation and archiving of gurmat sangeet, see The Gurmat Sangeet Project, http://www .gurmatsangeetproject.com.
} 


\section{Kirtan Across Continents}

Kirtan is sung and performed within a diversity of audiences, performers, and contexts. Like other spiritual music forms, Sikh kirtan carries with it associations and expressions of religious identity. Multiculturalism in Australia and North America, the 'New Age' of new religious movements in the West, post-1984 politicised Sikh consciousness, and efforts to recover 'lost' historical traditions are significant threads within this story of kirtan in the diaspora. As Townsend notes "one of the primary ways that Sikhs have carried with them Sikh ways of knowing and being is through their religious musical practices." 6 Thus, kirtan has come to be an important dimension of the Sikh diasporic imaginary which thus, as Axel postulates, "must be understood as an affective and temporal process rather than a place."7

Music, texts, and scriptures travel along with people as they travel and migrate and, as such, are listened to, performed, and recited while constituting new modes of cultural creativity and expression. The spiritually emotive essence of kirtan makes it a significant dimension of the Sikh diasporic imaginary in evoking spirituality as well as longing, belonging, assertion, and creativity. The meditative and sometimes evocative state associated with kirtan contributes to its continuing circulation and popularity in the diaspora as an integral part of the Sikh diaspora experience. In fact, kirtan is often evoked to represent Sikh identity, showing how its forms and styles are subject to contestation and scrutiny, alongside creativity and cultural production. There are therefore, as this chapter will highlight, many genres of kirtan in the diaspora, making it a dynamic spiritual music form.

The history of Sikh diaspora settlement contains many sounds of expression of movement, struggle, consolidation, and assertion. Some have even gone as far to argue that "among Sikhs the tradition of migration is in danger of becoming a culture,"8 showing the long-standing history of migration and its cultural deep-rootedness. While music, namely

6 Charles M. Townsend, "Gurbani Kirtan and the Performance of Sikh Identity in California," in Pashaura Singh (ed.) Sikhism in Global Context, (New Delhi: Oxford University Press, 2011). 208-209.

7 Brian Keith Axel, The Nation's Tortured Body: Violence, Representation, and the Formation of a Sikh "Diaspora," (Durham and London: Duke University Press, 2001). 426.

8 Gurharpal Singh and Darshan Tatla, Sikhs in Britain: The Making of a Community, (London: Zed Books, 2006). 31. 
bhangra, ${ }^{9}$ has been highlighted as an expressive and symbolic dimension of the Sikh/Punjabi diasporic experience, kirtan to date has been largely ignored in this respect. Sikh diaspora settlement provides a lens through which the conditions created for innovation and the continuation of kirtan can be understood.

The long history of global migration from Punjab since the nineteenth century has culminated in more than one million Sikhs being settled 'abroad.' Britain, the United States, and Canada account for three-quarters of this Sikh diaspora settlement, ${ }^{10}$ with settlement in Australia, Singapore, Malaysia, and different European countries constituting smaller populations. While one way of understanding community building is through actors, institutions and organisations, cultural production and expressive arts provide important insights into transformations of community. The routes and terms of migration have had a lasting impact upon institutionbuilding, community consolidation and cultural production in the multitude of places which constitute the Sikh diaspora.

\section{Migration, Artisans and Music: The Ramgarhias}

Having for the most part escaped the worst era of the colonial system of indenture, the initial routes for migration by Punjabis in the colonial labour system were through recruitment into employment contracts rather than indenture. ${ }^{11}$ While Punjab entered the colonial fold after other regions of South Asia due to its comparatively late annexation in 1849, colonial migration began around the mid-nineteenth century through recruitment under the British into the railways, police force, and security to places like Fiji, Malaya, and Hong Kong initially and then to East Africa to build the Ugandan railway, the construction of which began in 1896 .

The imperial migration to East and Southeast Asia and East Africa were skilled labour routes and thus impacted upon how these Sikhs fit into the occupational structure. The Sikh East African experience of colonial labour migration is in particular worthy of examination for our purposes here for two reasons. The first is due to its high skills base, which no doubt

\footnotetext{
9 See, for example, Anjali Gera Roy, Bhangra Moves: From Ludhiana to London and Beyond, (Aldershot: Ashgate, 2010).

10 Darshan S. Tatla, The Sikh Diaspora: The Search for Statehood, (London: UCL Press, 1999). 61.

11 Ibid. 46.
} 
impacted upon the development of gurdwaras which in turn saw the creation of institutions for kirtan to be taught and performed in the community. While the building of the railway was the initial attraction of Sikhs to East Africa, other skilled labour was sought after within this group of predominantly Ramgarhia Sikhs. Thus, this group, who also worked as builders, carpenters, teachers, electricians and other professions, began to branch out into trade and administrative positions, making them a considerable force within the Indian community in East Africa. Their skill base no doubt facilitated the high level of community development that occurred in East Africa from the 1920s to the 1960 .

The second is the fact that women and children also migrated to East Africa relatively early on in this migration history and thus were a central part of the establishment of community. This enabled conditions for cultural creativity and cultural transfer alongside education and community activities. Weddings were an important opportunity for singing and dancing, including giddha, boliyaan, sitniyaa and other folk geet, rooted in the age-old traditions of Punjabi wedding customs.

Within this milieu of cultural differentiation due to colonial racialised logic, East African Sikhs during this time developed a community spirit which was perhaps unprecedented in any other diaspora context. The East African context, as Bhachu ${ }^{12}$ points out, saw the rise of different types of Indian institutions like gurdwaras, Sikh clubs, and Ramgarhia associations all of which created a climate of community building, a pride around work ethic and the creation of religious and other institutions.

Notably, the first gurdwara was established in 1892 in Kilindini ${ }^{13}$ in Kenya followed by the creation of many gurdwaras being built wherever communities had settled from Mombasa to Nairobi to Uganda. Ladies satsangs (sing-alongs) as well as mixed gatherings of kirtan sung by the sangat or led by the resident granthi (priest) of the gurdwara were commonplace. It is therefore not surprising that the ubiquitous nature of music and culture within the experience of early to mid-twentieth century East African Sikhs in Kenya and Uganda has been an important tributary to subsequent global forms of kirtan.

This then travelled with the East African Sikhs as 'twice migrants'14 to the UK from the mid-196os to the early 1970s and explains for how this

12 Parminder Bhachu, Twice Migrants: East African Sikh Settlers in Britain, (London: Routledge, 1985). 23.

13 S. Kaur, Afro-Sikhs in Kenya: Nanak Parkash. Nairobi: Sikh Students Association, 1977. Cited in Tatla, The Sikh Diaspora, 1999. 50.

14 Bhachu, Twice Migrants, 1985. 1. 
group made their presence felt as a unique element of the South Asian presence in the U.K. It is also no wonder that there is a considerable presence of East African Sikhs in the contemporary bhangra music industry in the UK, with kirtan having provided a foundational base for other types of musical production.

The story of East African Sikh migration to the UK should not be seen as being representative of the British Sikh experience more widely as the Ramgharia Sikhs migrated to the UK during a relatively later time and with comparatively privileged class and cultural resources than their counterparts who migrated directly from India. Their relatively higher level of community organisation and networks which were transplanted from East Africa to the UK were an asset in marking out their distinctive East African Sikh identity. The presence of this group within the kirtan revivalist movement is worthy in how this configures with the Ramgarhia position within social hierarchy and the possibilities for mobility that religious orthodoxy and kirtan practice associated with this orthodoxy offer. ${ }^{15}$

\section{Sikh Migration from India}

Sikh presence in the UK, however, predated the East African Sikh arrival. The 'webs of empire'16 of the imperial relationship with Sikhs positioned Britain as a pivotal point for the emerging global Sikh diaspora for whom the post-war period marked a significant wave of migration from Punjab to Britain first under the voucher scheme and through increasingly restricted routes of access to work, and family sponsorship. One outcome of the consolidation of community in Britain was the British Sikh gurdwara movement, ${ }^{17}$ which resulted in the creation of Sikh institutions and places of worship. While community centres such as the Southall Community Centre were important venues for musical and cultural functions such as weddings and parties, religious institutions became another important marker of community presence.

15 H. McLeod, "Ahluwalias and Ramgarhias: Two Sikh Castes," South Asia, 4 (1974): 78-9o. Roger Ballard. 'Differentiation and Disjunction among the Sikhs' in Roger Ballard, ed., Desh Pardesh: the South Asian Presence in Britain (London: Hurst and Co. 1994), 111.

16 Tony Ballantyne, Between Colonialism and Diaspora: Sikh Cultural Formations in an Imperial World, (Durham: Duke University Press, 2006), 30.

17 See Gurharpal Singh and Darshan Tatla, Sikhs in Britain: The Making of a Community, (London: Zed Books, 2006.) for an empirically detailed discussion of the gurdwara movement in Britain during the twentieth century and the politics of leadership, identity, and community building. 
As early as 1908 the Khalsa Jatha of the British Isles (KJBI) was established which eventually led to the establishment of the first gurdwara in Shepherd's Bush, West London. While this gurdwara became the initial centre for Sikh celebrations and festivals, many of the services and kirtan were conducted by members of the sangat ${ }^{18}$ — most often musically untrained-who offered a range of skills in contributing to the rites, prayers and performance of kirtan.

\section{Professional Raagis}

Satsang style 'simple' shabads were commonplace in gurdwara kirtan services in an era predating the professionalised raagi migrants when it was common for gurdwaras to employ a granthi who along with his scriptural duties was also expected to fulfil the kirtan duties.

The first professional trained raagis began to visit the UK and North America in the 1970s during which time Bhai Avtar Singh, Dharam Singh Zakhmi, and Chattar Singh were amongst the many renowned raagis who brought traditional kirtan styles to the diaspora. Many of this first generation of professional raagis did not settle in the UK. This period coincided with a number of gurdwaras becoming established in the major towns and cities of the UK and North America.

Late in the 1970s, gurdwaras began to employ professional raagis, wages however were meagre and the raagis supplemented this through donations made by the sangat during the kirtan performance. This generation of raagis - whilst being classically trained, were shaped by an audience which was becoming increasingly attracted to the growing bhangra and Bollywood music industries. The sangat was easily impressed by popular kirtan styles in which shabad tunes were based on Bollywood songs.

Alongside this, sangat-led performance has also continued with the expansion of Sunday classes in Gurmukhi Punjabi, kirtan and classical instrumentation taught by members of the sangat. Raagis also act as teachers in the learning of shabad kirtan gurbani and in this capacity impart their styles and methods of learning kirtan through harmonium and vocal training upon the youth of the British Sikh community.

18 See Navtej K. Purewal, "The Sound of Memory: Interview with Singer Mohinder K. Bhamra," Feminist Review 100 (2012): 142-153. 


\section{The Commodification of Kirtan}

Apart from metropolises where gurdwaras were becoming established, the opportunities to listen to kirtan were limited in most parts of the Sikh diaspora during this time. This period coincided with the availability of music recordings on LP and subsequently tape. This provided an opportunity for the Sikh diaspora to listen to kirtan in their own homes. The release of the Bollywood-produced film 'Nanak Naam Jahaaz Hai' in India in 1969, followed in 1974 by the film 'Dukh Bhanjan Tera Naam,' provided a soundtrack for a diaspora hungry for music from Punjab most particularly the sounds of kirtan and Punjabi popular music.

Some of the best-known Bombay film playback singers provided the soundtracks and shabads such as 'Deh Shiva Var Mohe' (Mahendra Kapoor), 'Mere Sahib Mere Sahib' (Asha Bhosle), and 'Mitter Pyare Noon' (Mohd. Rafi) provided a link between the film and musical cultures of India to the diaspora. Copies of Bhai Gopal Singh Ragi's shabad kirtan album 'Mera Mujh Main' released in 1972 became extremely popular in the Sikh diaspora and could be found in most households possessing an LP player.

The ensuing cassette culture ${ }^{19}$ provided both a taste and listenership for kirtan. It was not until the late 1970s that shabad kirtan in India developed its own music industry. The kirtan music industry took root during this period and some of the raagis who performed on All India Radio in India and published recordings on cassettes became 'kirtan superstars'. This popularity attracted some of them to the UK and North America and during the early 1980s, Harbans Singh (Jagadari), Balwinder Singh Rangeela, and Harjinder Singh (Sri Nagar) were greeted with hundreds, sometimes thousands flocking to the gurdwaras to hear them perform. Their recordings became very popular and they paved the way for a second generation of popular kirtani's to visit and often settle overseas.

\section{Spiritual Followings: The Sants}

In the same period of the early 1980s a number of sants such as Sant Ishar Singh (of the village Rara in Punjab), Sant Gurdev Singh ('Bhai ki

19 Peter L. Manuel, Cassette Culture: Popular Music and Technology in North India, (Chicago: University of Chicago Press, 1993). 
Samadh'), and Sant Miha Singh (of Siahar in Punjab) travelled to the UK and North America and popularised what could be termed the 'dharna' style of kirtan. This was a participatory style of kirtan centring around simple, interpreted lyrics which involved the participation of the sangat in repeating those lyrics after the raagi. The charismatic personality of sants in drawing spiritual followings is a significant dimension of Sikh religious practice which, apart from LaBrack's ${ }^{20}$ study of sant followings in northern California, has been relatively unexplored in India or the diaspora. As a tradition the sant influence remains to this day, and the establishments of gurdwaras (such as those by Sant Miha Singh, Sant Gurdev Singh and Sant Amar Singh) and the regular visits by sants such as Ranjit Singh (Dhadrian) and Sant Maan Singh (Pihova) have ensured that the dharna style remains very popular in the diaspora.

\section{The Bhatras: A Pioneering Community}

In other parts of the UK such as Manchester, Glasgow and Birmingham, the varied configurations of community have produced an array of kirtan performance, in tune with the social base of the sangats. The significant bhatra community which is the oldest of all Sikh communities in the UK pioneered the push in the 1950 os to establish gurdwaras, ${ }^{21}$ a movement which other communities also joined and eventually took over. In 1949 B.S. Landa, a member of the Manchester bhatra community, arranged for a Guru Granth Sahib to be brought from India which was then installed in his front room on Monton Street. Soon thereafter a collection from the community raised enough funds to purchase another property on the same street to establish a gurdwara in $1953 .{ }^{22}$

As one reflection of life in Manchester at that time presents, the gurdwara was a focal point for identity and belonging for young children with kirtan providing a strong current for religious learning:

I associated with other Sikhs on Sundays. We used to go round to the Temple and meet everybody there. I liked singing hymns, even liked singing one

\footnotetext{
20 Bruce LaBrack, "Sants and the Sant Tradition in the Context of Overseas Sikh Communities" in K. Schomer and W.H. McLeod (eds.) The Sants: Studies in a Devotional Tradition of India, (Delhi: Motilal Banarsidass, 1987).

21 Singh and Tatla, Sikhs in Britain, 2006. 72.

22 Kitty Fitzgerald, Daljit Singh and Raj Kaur Singh (eds.) Speaking for Ourselves: Sikh Oral History, (Manchester: Manchester Free Press, 1986), 43.
} 
or two on my own. We used to get a prize for it, a pen and book or scarf or five shillings, something like that. ${ }^{23}$

The bhatra community in the UK has a strong tradition of collective singing and music, and this in part has contributed to the vibrancy of this community's maintenance of a strong community identity in comparison to other groups. The participatory dimensions of kirtan performance amongst men of the bhatra community is one characteristic which also marks out a distinctively gendered form of music, with women sometimes still wearing ghund (dupatta covering the face) and being largely absent from public performance of kirtan apart from as members of the listening sangat. The bhatra community, in many senses, were pioneering in asserting a visible and organised community identity while their socioeconomically marginal position within broader British Sikh society has concealed its contributions on a larger scale. Indeed, the starkly patriarchally gendered and endemically persistent working class features of Bhatra communities have contributed to this marginality when compared to the experiences of most other Sikh communities. ${ }^{24}$

The UK picture is neither a uniform one nor one which can be generalised about in terms of kirtan. Certainly, the British Sikh Gurdwara movement was a significant step towards asserting an identity and presence for recognition on the British social and religious landscape where gurdwaras became important venues for kirtan performance and listenership. Kirtan in the gurdwaras of Britain from the 196os promoted styles of learning and performance both in tune with the context of contemporary British Sikh identity formation as well as popular styles of kirtan in Punjab at the time. Thus, gurdwaras became places where interactions and innovations around kirtan's musical performance occurred. Raagis from India came with mixed training backgrounds, often classically trained through Sikh missionary colleges in India but also having performative versatility in singing to audiences in popular, sometimes Bollywood film tunes. This cohort of émigré raagis embodied both classical and 'pop' genres of kirtan and became one important conduit through which kirtan was transmitted. The teaching of shabad gurbani to children to simple tunes with harmonium and tabla was the initial model of kirtan learning to younger generations of Sikhs. Gurmat Khalsa camps held not only across the UK but also

23 Fitzgerald et al., Speaking for Oursetves, 1986, 45-46.

24 Roger Ballard. 'Differentiation and Disjunction among the Sikhs' in Roger Ballard, ed., Desh Pardesh: the South Asian Presence in Britain (London: Hurst and Co. 1994), 88-116. 
in Canada and the U.S. during summer vacation times also promoted this conventional style of kirtan learning. While this was the official model of kirtan and spiritual authority as projected by the gurdwaras, there was also a critique of these conventions as modernist endeavours.

\section{Revivalist Movements}

The consciousness of the next generation of Sikhs who had had the benefits of security provided by Sikh sacred institutions and an elevated identity consciousness after 1984 were now hungry for deeper historical knowledge of kirtan's classical base. The renewed interest in traditional instruments such as the taus, jorhi, rabab, saranda, sarangi, and dilruba which were played during the eras of the Gurus represents a heightened consciousness which is critical of Sikh institutional approaches to kirtan. While much of this classical revivalism has taken place in India, the diaspora has been a fertile ground for explorations of kirtan's historical and classical base.

The aims and objectives of the two academies earlier mentioned, the London-based Raj Academy and the Birmingham-based Gurmat Sangeet Academy, are similar. In fact, both academies find their origins in terms of musical tuition within the Namdhari movement and in particular under the guidance of Surjeet Singh Aulakh, a highly accomplished Sarangi player who has guided the musical knowledge of both the academies. They promote Gurmat Sangeet as "the sacred art and science of singing and playing hymns from the Siri Guru Granth Sahib in the prescribed rags using the original string instruments." 25

Both academies have actively promoted the practice of Gurmat Sangeet and are presenting a rather different entry into kirtan from the former examples. Having a pedagogical and teacher-training dimension to the teaching of classical gurmat sangeet, they promote what they believe is 'correct practice' through education and a rejection of modernising and commercial influences on contemporary kirtan which according to Professor Surinder Singh:

Due to modern influences in Sikh music today, most raagis ignore the prescriptions of the raags on the hymns, so that Kirtan is no longer a spiritual discipline, but a form of entertainment. "A spiritual discipline given by

25 See http://www.rajacademy.com/content/about-us/index.php. 
masters cannot yield its desired effects if the rules are changed because of insufficient education or commercial considerations. ${ }^{26}$

The Raj Academy's troupe of multi-ethnic kirtaniyas and the Gurmat Sangeet Academy's wide appeal to younger generations in particular in teaching and performing Gurmat Sangeet exhibit kirtan as a global form which has taken different routes of innovation and establishment in the diaspora. This not only reflects how it has travelled with communities wherever they have settled but also how it has become revived in the diaspora through attempts to preserve its historical roots.

This movement towards a revival and recovery of kirtan from the modernising tendencies of the SGPC forces ${ }^{27}$ is shared by other such movements in India and North America which seek to popularise the classical form of kirtan performance. The distinction between the Raj Academy/ Gurmat Sangeet Academy approach from that of the classes ordinarily taught at gurdwaras across the UK is that of a high, historical musical culture of kirtan versus a sangat-based participatory form. Emphasis is placed on the delivery of shabads strictly in the raags within which they are composed and also on the use of stringed instruments such as the dilraba, taus, saranda, sarangi, and rabab.

\section{New Worlds of Kirtan: North America and the UK}

At the same time that Sikh movement to East Africa had begun in the late nineteenth century, the first Sikh settlers arrived in British Columbia from the Far East after completing their terms of service in the police or army. The British Empire's territories provided a range of destinations for male Sikh migrants in search of economic opportunity. ${ }^{28}$ These early migrants were men who travelled in mixed cohorts in an era which was not one of unified Sikh ethos as had not yet taken root in Punjab, but rather of a

26 http://www.rajacademy.com/content/about-us/download/ra_prospectus.pdf.

27 For a discussion of the application of the Sikh Rahit Maryada on the performance of kirtan in SGPC gurdwaras in India, see Navtej K. Purewal, "Sikh/Muslim Bhai-Bhai? Towards a Social History of the Rababi Tradition of Kirtan," Sikh Formations 7/3 (2011): $365-382$.

${ }_{28}$ This era of migration to North America was by no means fluid or without struggle. The well known voyage of the Komagata Maru, a ship carrying 376 passengers was refused entry on arrival at Vancouver Harbour in May 1914 and resulted in a consciousness around discrimination and the need for collective mobilization and protest against draconian laws of exclusion. See Baba Gurdit Singh, Voyage of Komagata Maru or India's Slavery Abroad, (Chandigarh: Unistar, [1928] 2007). 
pan-'Hindoostani' one, particularly in light of the anti-colonial sentiments of the time. These male Indian workers lived, travelled and worked amongst mixed groupings of religion, caste, and region. ${ }^{29}$ Therefore, it is likely that more secular or shared forms of music providing a greatest common factor such as folk tunes would have been more popularly sung amongst these male 'pioneers' for whom other forms of identification would have prevailed over a Sikh religious identity. ${ }^{30}$

The struggle for entry, rights and recognition of early settlers during the late nineteenth to the mid-twentieth century in the U.S. and Canada shows a long battle against the Anti-Asian League in Canada, the Asiatic Exclusion League in the U.S., and draconian measures of the state authorities to exclude Asians and to prevent ownership of land and migration of women. ${ }^{31}$ California and British Columbia were the sites where these struggles took place with men looking for work in the lumber industry in Canada and farming in California. Sikh men during this time were unable to amass the community resources which their East African counterparts were doing during this time, due to the formal stipulations which prevented them from settling down with women from India and purchasing agricultural land which impacted heavily on the nature of community development. ${ }^{32}$ Inter-marriage with Mexican women was one outcome of these restrictions and most of these early migrants lived in isolated, rural settings, thus not conducive towards the establishment of a public Punjabi or Sikh cultural life. Indeed, many offspring of this generation spoke English and/or Spanish, were sometimes baptised Catholics and became a part of the migrant mileu of California which offered refuge to those who were not deemed "free white persons". 33

29 It is also important to note that that the formal identity 'Sikh' had not been registered as a separate category in the Census until 1921, and that the Singh Sabha Movement of the 1920 s had not yet evoked a sense of identity across the Sikh panth in religious terms as we know it today. This was a time of identity formation not only in India but also in the diaspora.

30 Karen Leonard, "Pioneer Voices from California: Reflections on Race, Religion and Ethnicity," in N.G. Barrier and V.A. Dusenbery (eds.) The Sikh Diaspora: Migration and the Experience Beyond Punjab, (Delhi: Chanakya Publishers, 1989), 120-139.

31 The Naturalization Act of 1790 was passed through the U.S. Congress to limit citizenship to 'free white persons' and was later amended in 1868 to include African Americans. The Exclusion of Asian Indians Act in 1917 was used as a means of creating a racial category for 'Asian Indians' who had an ambiguous relationship to the existing Chinese Exclusion Acts which applied to 'Orientals.'

32 Karen Leonard, Making Ethnic Choices: California's Punjabi Mexican Americans, Philedelphia: Temple University Press, 1992. 62-78.

33 Ibid. 101-120. 
Despite this, the resistance to the anti-Asian legislation must not be dismissed as it resulted in the establishment of the Khalsa Diwan Society and saw the establishment of the first gurdwara in Stockton California in $1915^{34}$ with a symbolic presence of Ghadar Party ${ }^{35}$ exiles also becoming a part of this fledgling community. While Punjabi folk music would have circulated amongst these early Sikh male migrants through popular lok geet, the lack of formal status and a limited access to religious institutions contributed to kirtan not having the conditions to flourish. It is also possible to argue that the collective consciousness of these male migrants was formulated around their racialised position vis-à-vis anti-Asian sentiments, gender and emasculation, and class rather than around a spiritually formed sangat.

However, the establishment of a gurdwara in Abbotsford near Vancouver in Canada in 1912, ${ }^{36}$ in Stockton in 1915, and subsequent smaller gurdwaras alongside informal gatherings in private spaces to mark occasions such as Vaisakhi and Guru Nanak's birthday maintained a sense of cultural identity throughout this period. Once the restrictions on property ownership and citizenship were lifted in the 1950s, new forms of community which voiced identity and presence began to emerge with Punjabi women from rural areas in India migrating through marriage to join men in California and Canada. ${ }^{37}$ This new era marked the beginning of growth of this community which had once been under threat of disappearing.

It was the 1960s and 1970s when 'brain drain' migration from different parts of India began to North America, when doctors, engineers, and scientists were recruited to occupy the upper-tiers of the occupational structure arrived. With that phase, social capital and cultural resources were mobilised with both men and women becoming a part of this middle and upper middle class Sikh community who had both social standing

\footnotetext{
34 Tatla, The Search for Statehood, 1999. 53.

35 See Harish Puri, Ghadar Movement: Ideology, Organisation and Strategy, (Amritsar: Guru Nanak Dev University Press, 1983).

36 In 1911 the Trethewey family who owned the Abbotsford Lumber Company, the largest employer of Sikh workers, donated lumber for the construction of a gurdwara. This was a milestone not only in terms of it showing a recognition of multiculture within Canada but it also provided a place for gathering, congregation and community which facilitated further community development while also contributing to Punjabi social life at the time.

37 Verne A. Dusenbery notes how early Sikh identity as it developed in North America from the middle of the twentieth century was influenced by a Doabi clean-shaven, turbanless Jat dominance. See his Sikhs at Large: Religion, Culture, and Politics in Global Perspective, (New Delhi: Oxford University Press, 2008), 21-23.
} 
within the class structure of mainstream American and Canadian society while also having security, educational background and skills to promote community institutions on a higher level. Initial diwan ceremonies during the 1960 s and 1970s, however, were conducted in private homes or in rented halls until there was enough sangat and leadership to physically establish gurdwaras.

Outside of the metropolises, most Sikh services were self-run, ranging from the installation and recitation from the Guru Granth Sahib, the singing of kirtan, the ardas, and cooking and serving of langar. Punjabi Sunday classes were taught by members of the sangat, namely parents, mirroring the Sunday school model of churches in the U.S. became a part of the weekly schedule. The do-it-yourself spirit of the creation of gurdwaras saw a heightened confidence of Sikhs to run their own services and to mark their presence on the maps of Canada and the United States. This generated a status for the authority of the sangat over the raagi, as this stream of professionalised raagis were employed by the gurdwara management committees and accountable as 'employees' whose immigration status and income was also tied to the approval of the sangat. The politics of recognition which began during this phase has continued in the present in North America with the professional class of North American Sikhs at the helm of legal and public cases emerging out of this history of consolidation.

\section{American 'Gora' Sikhs}

In the late 196os Harbhajan Singh Puri, who came to be known as Yogi Bhajan or Siri Singh Sahib by his followers, began a spiritual movement in southern California called $3 \mathrm{HO}$ (Happy, Holy, Healthy Organization) which had a predominantly white middle class following. Indeed, as Dusenberry notes, early $3 \mathrm{HO}$ recruits of this time were "refugees from the counterculture" who at this stage were more attracted to Yogi Bhajan's charismatic style and teachings of Kundalini yoga rather than being attracted to Sikhism. ${ }^{38}$ Yogi Bhajan later in the 1970 os began to move towards Sikhism and spreading a Khalsa identity for his converts to this new religious movement. Yoga as well as kirtan became a central part of the spiritual practice

38 Verne Dusenbery, "Punjabi Sikhs and Gora Sikhs: Conflicting Assertions of Sikh Identity in North America," in Joseph T. O'Connell, Milton Israel and Willard G. Oxtoby (eds.) Sikh History and Religion in the Twentieth Century, (Toronto: University of Toronto, Centre for South Asian Studies, 1988), 334-55. 
which was being preached by Yogi Bhajan. Indeed, the fact that most converts took on the externally visible markers of Khalsa identity (the $5 \mathrm{Ks}$ ) and became more devoutly practicing Sikhs than most of their Punjabi counterparts became a point of contention and separation between the two groups of 'American or Gora Sikhs'39 on the one side and Punjab Sikhs on the other.

What might be understood as a 'culture clash' between Yogi Bhajan's disciples and Punjabi Sikhs has resulted in a bifurcated Sikh identity in the U.S. which acknowledges these two tangential paths within the Sikh fold- one of the 'new age' and the other of Punjabi Sikhs emigrated from the 'homeland'. For a short period of time in the 1970s, where Sikh Dharma Ashrams held diwan services, Punjabi Sikhs also attended in places where there were no existing Punjabi-run gurdwaras. These interactions led to a number of public perceptions on both sides of difference of interpretation and practice between the two groups which has seen 'Punjabi Sikhs' to view 'Gora Sikhs' as 'Sikhs of a different kind. ${ }^{40}$ However, these differences have overtime emerged and dissolved depending on the sensibilities of identity at the time. For instance, it was not uncommon in the 1970s and early 1980 for the diwan service and langar at an Ashram to resemble the gurdwara conventions, sometimes with Amritdhari Punjabi Sikhs even being invited to recite the vaak or ardas. Nonetheless, an unspoken yet mutually agreed social distance has been instated in maintaining religious ties without close interaction. ${ }^{41}$

The form and style of kirtan sung in the Sikh Dharma Ashrams resembles American folk music accompanied by guitar, table, and chanting with influences of classical or popular kirtan. The participatory nature of this style, however, has similar effects on the sangat in encouraging all to 'sing along' as the satsang style done in Punjab-run gurdwaras. Kirtan of this 'new age' style has become popularised on the mainstream western music stage not least through Snatam Kaur, earlier mentioned, and Singh Kaur who sings in Celtic chant style accompanied by the harp.

On the Punjabi side of the new age, the 1970s and 1980s in the U.S. saw a consolidation of Punjabi Sikh communities through the reunification of families through the sponsorship of relatives of 'brain drain' migrants.

39 Dusenbery, Sikhs at Large, 2008, 27-35.

40 Ibid., 16.

41 Jakobsh, “3HO/Sikh Dharma of the Western Hemisphere," Religion Compass (2008): $1-24$. 
In the U.S. this took place through the family reunification and sponsorship program in the U.S. and in Canada. This resulted in a 'filling out' of Sikh communities whereby the new emigres often did not have the same educational or professional level as their relatives who had sponsored them. However, the knowledge, skills and willingness in undertaking the requirements of running gurdwaras was significantly strengthened by the arrival of this second group of Sikh migrants who further boosted the gurdwaras into bustling centres of community activity and engagement. Many of the previously self-run gurdwaras began to have enough membership and financial support to bring priests or granthis from India on the Religious Worker visa. Thus, more institutionalised gurdwaras brought with them an infrastructure to support such activities as the teaching of kirtan. Meanwhile, the ladies satsang form of kirtan has continued to exist alongside the raagi forms, literally as the popular women's voice of the sangat. The expansion of Sikh religious activity through the diversity of skills, background and resources during this time benefitted the gurdwaras in terms of boosting numbers in the sangat as well as providing a larger pool of sevadars and donors.

\section{Kirtan in the Diaspora after 1984}

The 1980 os were a watershed in terms of Sikh diaspora identity with the events of 1984 creating almost overnight a politicised Sikh religious identity within this diversified community in the U.S. and Canada. From being a community of 'pioneers' in the experiences of both early British Columbia and California Punjabi male settlers or of the 'brain drain' high level professional recruits, the Sikh diaspora in North America by the early $1980 \mathrm{~s}$ had the institutional organisations to represent and service the demands of congregations settled there.

When Operation Bluestar took place on June 6, 1984 Sikh diasporic communities in North America not only had a voice but also had resources, institutions, and public recognition to express a critique and often an anti-Indian state position. However, as Tatla notes, little documentation exists on the settlement of post-1984 refugees yet the reluctance and often callous immigration policies in Canada, the U.S., and Europe failing to recognise the plight of Sikh male refugees illustrates the limits to which the Sikh diaspora could absorb them. ${ }^{42}$ Khalistani politics became a part of Sikh diasporic consciousness as a formative part of many gurdwaras

42 Tatla, The Sikh Diaspora, 1999. 58-62. 
in North America during that time. Sermons in gurdwaras as well as kirtan practice were influenced by this heightened consciousness. It is not surprising that this time also marked an upsurge of interest in kirtan as it became symbolic of Sikh identity.

Contemporary Sikh identity in the diaspora as we know it today crystallised in 1984 after the storming of the Golden Temple in Amritsar when the links between diasporic locations and Punjab became stronger than had previously been the case. The sense of consciousness which was roused in the diaspora at this time was unprecedented and generated new forms of cultural and religious activism around Sikh politicised identity. With gurdwaras and communities now established in different diaspora locations, kirtan had a base to become one conduit through which this globalising consciousness was spread. The Akhand Kirtani Jatha (AKJ) has its roots with its founder Bhai Randhir Singh in the nineteenth century during British colonial rule. They promote a rigorous interpretation of the rahit (code of conduct) of Guru Gobind Singh as set out in 1699 when the Khalsa was institutionalised. Thus, the AKJ in the post-1984 era was in a strong position to mobilise sentiments and, in this respect, their emphasis on the importance of kirtan had a tremendous influence upon the Sikh diaspora's exposure to their style of kirtan, namely in samagam (kirtan programmes or gatherings lasting several days) ending with rainsbai (all night kirtan). ${ }^{43}$

The kirtan performed at an AKJ rainsbai has a distinctive style and form which emphasises gurmantra (God's true name), naam simran (meditation on God's name), the Dasam Granth of Guru Gobind Singh in addition to the Guru Granth Sahib, and of the amrit (baptism) ceremony. Unlike other more 'purest' endeavours to recite kirtan within the denoted raag and taal and with traditional instrumentation, the AKJ style is repetitive and 'transical' so that initiates and the sangat can follow and sing along with fervour along to simple, accessible tunes accompanied by tabla and harmonium. The use of breath and repetition are key markers of the AKJ style of kirtan in this respect and the collective singing of gurmantra through repetition contributes to the atmosphere of the rainsbai. Beginning with a slow, simple tune, the intensity of the atmosphere builds into

\footnotetext{
43 There are two notable translations of the meaning of rainsbai. The first is that 'rain' means 'night' and sabha means 'all' or 'sangat'. Another translation still denotes rain to mean 'all night' but that asbai means 'shortened'. See J. Barrow, "The Akhand Kirtani Jatha: A Local Study of the Beliefs and Practices of Its Members," International Journal of Punjab Studies 8/1 (2001): 97-116.
} 
an ecstatic and rapturous spiritual setting. As Barrow notes in her study of the AKJ in Southall:

At regular intervals there were several minutes of repeating the gurmantra increasingly fast until the pace was almost frenetic and sounds could be heard coming as if from within the person ... My perception was of a primal sound that was coming from within their very being. It was not constrained by the need to resort to the cerebral and articulate words that could be understood by other people; it was direct from their inner being and bypassed their brains so that there was no interference between their inner being and its expression. ${ }^{44}$

The lack of constraint which Barrow refers to is at the crux of what distinguishes the AKJ's more populist style of repetitive, collective recitation from the revivalist kirtan projects of the Raj Academy and the Gurmat Sangeet Academy. The AKJ samagams of North America and the UK in particular articulated this freedom from constraints in raising the consciousness of post-1984 diaspora Sikh identity through kirtan and the potent simplicity of the power of kirtan through the repetition of 'Vaheguru'. For the Sikh diaspora youth of the mid-1980s to the mid-1990s who were less fluent in Punjabi and knowledgeable about gurbani, the rainsbai kirtan movement led to an awakening of a generation. Tat-Khalsa Sikh identity became not only identifiable through tangible gatherings and a consolidation of community networks, but also was a means by which the youth could be socialised within their communities and taught the rahit which became significant to the identity base of younger generations of Sikhs.

The idea of Khalistan indeed flourished in these gatherings which made the samagam events an integral part of the Sikh imaginary of post-1984 Sikh identity. Anti-Indian government discourse and an assertive Gursikh identity were a driving force behind the popularisation of the AKJ rainsbai kirtan. While there are prevalent associations with the AKJ to an essential gursikh, Khalsa identity and practice, in reality their kirtan practice and performance remains very much within the popular realm and not the classical form but nonetheless has made a significant mark on kirtan in the diaspora. Indeed, the AKJ and the samagam movement of kirtan is but one of many movements which followed on from the events of $1984 .{ }^{45}$ As Tatla notes, the reaction to 1984 in the diaspora marked a "call for

\footnotetext{
44 J. Barrow, "The Akhand Kirtani Jatha," (2001): 103.

45 For an in-depth exploration of the socio-political fall-out of 1984 and of the more recent resurgence of the image of Jarnail Singh Bhindranwale, see Pritam Singh and Navtej
} 
revival of ethnic consciousness" ... for which "an initial mobilization was easy and spontaneous." 46 It is not surprising then that a renewed emphasis upon the importance of maintaining a distinctive Sikh identity in the North American and British contexts through observance of amrit saw an estimated several hundred clean-shaven Sikhs becoming baptized. ${ }^{47}$ Kirtan as a creative, musical form accompanied this movement of heightened religious identity one of the tangible and enjoyable practices associated with becoming baptized and taking amrit.

\section{Conclusion}

The three decades which followed the aftershocks of 1984 have seen an increased interest in kirtan in the search for new expressions and performances of identity and tradition. The heightened interest in the medieval forms of kirtan as performed by the Gurus, kirtanis, and raagis of those times began in the late $1990 \mathrm{os}$ in the form of revivalism. There is a certain amount of cynicism about the popular, commodified style of kirtan as revealed in studio recordings of raagis who have sold many CDs within the burgeoning market for kirtan. However raagis are still a considerable force in the performance of kirtan across the Sikh diaspora. This cynicism saw a move towards reinstating the classical instruments in the Golden Temple in Amritsar by the SGPC and in a more widespread encouragement of the revival of the traditional, classical form of kirtan. The drive for this has come from a number of different quarters and has seen many raagi jathas making steps towards performing within the classical or traditional mode and strategically moving away from the modern. The complexities which have emerged out of this classical revivalism show its historical embeddedness within the modernising forces of the Singh Sabha movement of the early twentieth century ${ }^{48}$ out of which the raagi jathas of today have emerged. The diaspora dimension of kirtan's evolution, however, shows both a desire to connect with a global Sikh identity while also asserting a historical tradition which predates the colonial encounter and which exhibits a musicality symbiotically connected with

K. Purewal, “The Resurgence of Bhindranwale's Image in Contemporary Punjab," Contemporary South Asia 12/2 (2013): 1-15.

46 Tatla, The Sikh Diaspora, 1999. 200.

47 Ibid.

48 Bob van der Linden, "Sikh Music and Empire," Sikh Formations 4/1 (2008): 385. 
the scriptures for which they were composed. The Sikh diaspora thus has been a site at which the boundaries of Sikh kirtan have been negotiated, innovated, and performed, placing it simultaneously as a classical, medieval form while also being a modern, evolutionary one.

\section{References}

Axel, Brian Keith. The Nation's Tortured Body: Violence, Representation, and the Formation of a Sikh "Diaspora," (Durham and London: Duke University Press, 2001).

Ballantyne, Tony. Between Colonialism and Diaspora: Sikh Cultural Formations in an Imperial World. Durham: Duke University Press, 2006.

Ballard, Roger. 'Differentiation and Disjunction among the Sikhs' in Roger Ballard, ed., Desh Pardesh: the South Asian Presence in Britain (London: Hurst and Co.) 88-116, 1994.

Barrier, N.G. and Verne A. Dusenbery (eds.) The Sikh Diaspora: Migration and the Experience Beyond Punjab. Delhi: Chanakya Publications, 1989.

Barrow, J. "The Akhand Kirtani Jatha: A Local Study of the Beliefs and Practices of Its Members," International Journal of Punjab Studies 8/1 (2001): 97-116.

Bhachu, Parminder. Twice Migrants: East African Sikh Settlers in Britain. London: Routledge, 1985 .

Dusenbery, Verne A. 'Punjabi Sikhs and Gora Sikhs: Conflicting Assertions of Sikh Identity in North America' in Joseph T. O'Connell, Milton Israel and Willard G. Oxtoby (eds.) Sikh History and Religion in the Twentieth Century, Toronto: University of Toronto, Centre for South Asian Studies, pp. 334-55, 1988.

—. Sikhs at Large: Religion, Culture, and Politics in Global Perspective. New Delhi: Oxford University Press, 2008.

Fitzgerald, Kitty with Daljit and Raj Kaur Singh (eds.) Speaking for Ourselves: Sikh Oral History. Manchester: Manchester Free Press, 1986.

Jakobsh, Doris. "3HO/Sikh Dharma of the Western Hemisphere: The 'Forgotten' New Religious Movement?." Religion Compass 10 (2008): 1-24.

Kalra, Virinder S. Sacred and Secular Musics: A Postcolonial Approach. Bloomsbury: London, 2014.

Kaur, Shyrone. "The Larrikin Pied Piper from Oz." Sikh Spectrum Monthly 12 (2003): http:// sikhspectrum.com/2003/05/the-larrikin-pied-piper-from-oz/.

Kaur, S. Afro-Sikhs in Kenya: Nanak Parkash. Nairobi: Sikh Students Association, 1977.

Khabra, Gurdeep J.S. "Music of the Sikh Diaspora: Devotional Sounds, Musical Memory and Cultural Identity." Sikh Formations 8/2 (2012): 147-170.

LaBrack, Bruce. "Sants and the Sant Tradition in the Context of Overseas Sikh Communities" in K. Schomer and W.H. McLeod (eds.) The Sants: Studies in a Devotional Tradition of India. Delhi: Motilal Banarsidass, 1987.

Leonard, Karen. "Pioneer Voices from California: Reflections on Race, Religion and Ethnicity." In N.G. Barrier and Verne A. Dusenbery (eds.) The Sikh Diaspora: Migration and the Experience Beyond Punjab. Delhi: Chanakya Publishers, 1989.

—. Making Ethnic Choices: California's Punjabi Mexican Americans. Philadelphia: Temple University Press, 1992.

Manuel, Peter L. Cassette Culture: Popular Music and Technology in North India. Chicago: University of Chicago Press, 1993.

McLeod, Hew. "Ahluwalias and Ramgarhias: Two Sikh Castes." South Asia 4 (1974): 78-90.

Purewal, Navtej K. "The Sound of Memory: Interview with Singer Mohinder K. Bhamra." Feminist Review 100 (2012): 142-153.

"Sikh/Muslim Bhai-Bhai? Towards a Social History of the Rababi Tradition of Kirtan." Sikh Formations 7/3 (2011): 365-382. 
Puri, Harish. Ghadar Movement: Ideology, Organisation and Strategy. Amritsar: Guru Nanak Dev University Press, 1983.

Roy, Anjali G. Bhangra Moves: From Ludhiana to London and Beyond. Aldershot: Ashgate, 2010.

Singh, Baba Gurdit. Voyage of Komagata Maru or India's Slavery Abroad. Chandigarh: Unistar, [1928] 2007.

Singh, Gurharpal and Darshan Tatla. Sikhs in Britain: The Making of a Community. London: Zed Books, 2006.

Singh, Pritam and Navtej K. Purewal, "The Resurgence of Bhindranwale's Image in Contemporary Punjab," Contemporary South Asia, Vol. 12, No. 2, June 2013: 1-15.

Tatla, Darshan S. The Sikh Diaspora: The Search for Statehood. London: UCL Press, 1999.

Townsend, Charles M. "Gurbani Kirtan and the Performance of Sikh Identity in California." In Pashaura Singh (ed.) Sikhism in Global Context. New Delhi: Oxford University Press, 2011.

van der Linden, Bob. "Sikh Music and Empire: The Moral Representation of Self in Music." Sikh Formations 4/1, 2008, 1-15. 
